
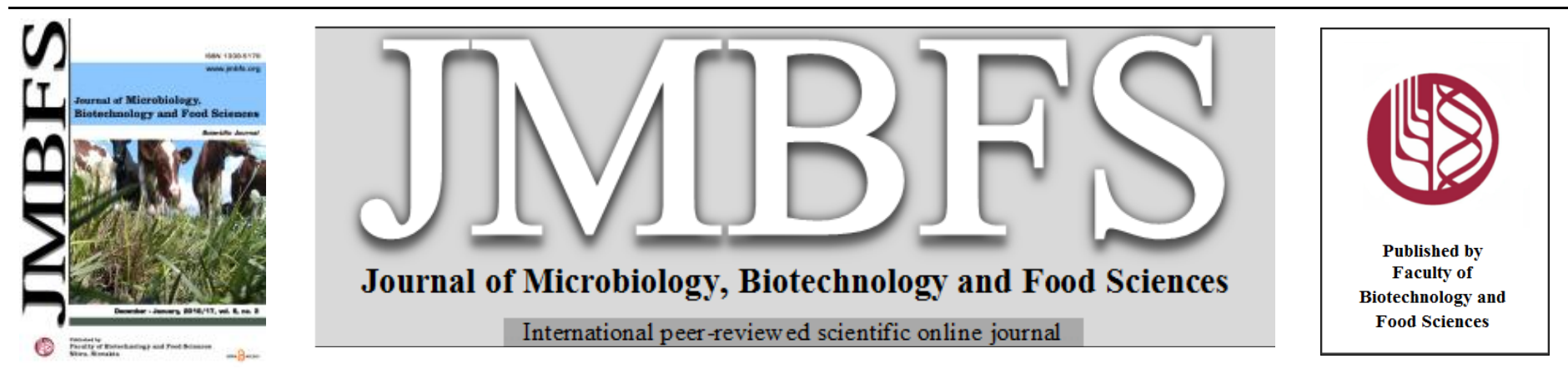

\title{
CHARACTERIZATION OF POTENT EXOPOLYSACCHARIDE PRODUCING BACTERIA ISOLATED FROM FRUIT PULP AND POTATO PEELS AND ENHANCEMENT IN THEIR EXOPOLYSACCHARIDE PRODUCTION POTENTIAL
}

\author{
Avni Vaishnav ${ }^{I}$, Kinjal Upadhyay ${ }^{1}$, Devayani Tipre ${ }^{1}$, Shailesh Dave ${ }^{2} *$
}

\author{
Address(es): Shailesh Dave, \\ ${ }^{1}$ Department of Microbiology and Biotechnology, School of Sciences, Gujarat University, Ahmedabad 380009, Gujarat, India. \\ ${ }^{2}$ Department of Forensic Science, School of Sciences, Gujarat University, Ahmedabad 380009, Gujarat, India, +91 9712565864.
}

*Corresponding author: shaileshrdave@ yahoo.co.in

doi: 10.15414/jmbfs.2016/17.6.3.874-877

\section{ARTICLE INFO}

Received 4. 4. 2016

Revised 24. 8. 2016

Accepted 2. 9.2016

Published 1. 12. 2016

Regular article

OPEN 2 ACCESS

\begin{abstract}
Exopolysaccharides (EPS) are environment friendly natural polymers secreted by microorganisms in the surrounding medium. Due to the presence of unique structural composition, EPS shows diverse applications such as in food formulations, pharmaceutical, cosmetics industry, etc. In the present investigation for the isolation of EPS producing bacteria, 30 samples comprising 14 fresh fruits, 14 spoiled fruits, 1 fresh potato peels and 1spoiled potato peels were inoculated on 4 different solid media containing sucrose, glucose and galactose as carbohydrate substrate and MRS agar (MRSA). The bacteria producing higher exopolysaccharide were screened among bacteria isolated from fresh and spoiled fruits and potato peels. Total 105 EPS producing colonies were obtained, out of which 17 isolates, which showed viscosity more than $0.1060 \mathrm{~m} . P a S^{-1}$ were selected. Based on $16 \mathrm{~S}$ rRNA gene sequence analysis, 17 isolates, which represents 8 genera, out of this $40 \%$ isolates belong to genera Bacillus. Among the carbohydrate studied sucrose proved to be the choice of the isolates for EPS production as compared to other sugars. When SYE and EPS media were compared, EPS medium was found to be the best except for the isolate SR17. The selection of EPS medium as medium of choice, sucrose as source of sugar and its 5\% concentration in the medium enhanced EPS production as high as $440 \%$ higher as compared to SYE medium.
\end{abstract}

\section{INTRODUCTION}

Exopolysaccharides (EPS) are key components of biofilm, which determines physico-chemical, and biological properties of biofilm formation. The exopolysaccharide play an important role in allowing microbes to live continuously at high cell densities in a stable mixed population of biofilm communities. Bacteria that produce exopolysaccharides have been identified from a variety of ecological niches and it is apparent that precise role played by exopolysaccharides is dependent on the natural environment, from which they are isolated. Ability to produce exopolysaccharides is a direct and logical response to selective pressures in that natural environment (Weiner, 1997).

EPS are used in food, textile, detergents, beverages, pharmaceutical (Nwodo et al., 2012), biotechnology, agricultural, paper, paint, cosmetic, medical and petroleum industries (Quesada et al., 1993) drug delivery (Sosnik, 2014), cancer therapy (Zhang et al., 2013) and in the formulation of the culture media due to their unique structure and physical properties. Some of these applications include their use as emulsifiers, stabilizers, binders, gelling agents, coagulants, lubricants, film formers, thickening and suspending agents (Sutherland, 1998). Due to their bioactive role and their extensive range of applications increasing attention is being paid to the production of these biomolecules. A new approach to encounter EPS with novel properties might entail investigating different environments. Isolation of bacteria from fresh vegetables and fruits, ready to eat salads (Trias $\boldsymbol{e}$ al., 2008a), citrus fruits waste (Marína et al., 2007), vegetable salads (Wright $\boldsymbol{e t}$ al., 1976), processed vegetables (Franzetti et al., 2005) dried fruits (Askari et al., 2012) have been done but with the importance of these bacteria in food spoilage (Nguz et al., 2005), pathogenicity (Palacio et al., 2012), antibacteria activity (Askari et al., 2012) and production of organic acids (Aslim et al., 2005; Trias et al., 2008b; Mridul and Preethi, 2014). To the best of our knowledge, no data are available for the isolation of EPS producers from potato peels and fruit pulp. Thus, in this context attempts were done to isolate EPS producing bacteria from potato peels and fruits. Work was also carried out to enhance their EPS production potential.

\section{MATERIAL AND METHODS}

\section{Screening and isolation of exopolysaccharide producing bacteria}

From the local market 14 types of fresh fruits and potato peels were procured and used for isolation of EPS producing bacteria. One gram pieces of fresh fruit and potato peels were homogenized in $10 \mathrm{ml}$ sterile peptone broth and incubated at $28 \pm 2{ }^{\circ} \mathrm{C}$ for $24 \mathrm{~h}$. After incubation, 10 folds serially diluted suspensions were prepared and $0.1 \mathrm{ml}$ aliquots were spread on yeast extract (YE) agar plates containing glucose, galactose or sucrose as carbon source. Fruits were stored at $28+2{ }^{\circ} \mathrm{C}$ and were allowed to spoil and after every 15 days, isolation was performed up to two months as mentioned for fresh samples. Plates were incubated for $48 \mathrm{~h}$ at $28 \pm 2{ }^{\circ} \mathrm{C}$. Mucoid colonies were screened and re-streaked on another agar plate with the same composition to obtain a pure culture. de Man, Rugosa and Sharp (MRS) medium (Atlas and Parks, 1997) was also used for isolation. Isolated cultures were characterized on the basis of colony morphology, microscopic observations and routine biochemical tests. The identification work was done according to the methods described in Bergey's Manual of Systematic Bacteriology (Brenner et al., 2005; Vos et al., 2009). Selected cultures were further identified by $16 \mathrm{~S}$ rRNA partial gene sequence analysis.

\section{Ehancement in EPS production}

EPS production was carried out in $250 \mathrm{ml}$ Erlenmeyer flasks containing $100 \mathrm{ml}$ of medium. The base medium contains ( $\mathrm{g} / \mathrm{L})$ : yeast extract $1.0 ; \mathrm{MgSO}_{4} 0.5$; $\mathrm{KH}_{2} \mathrm{PO}_{4} \quad 1.0$ and glucose/galactose/sucrose/mannitol 30.0 as a source of carbohydrate. The $\mathrm{pH}$ of all four media was adjusted to 7.0. All media constituents were sterilized at $121{ }^{\circ} \mathrm{C}$ for $20 \mathrm{~min}$ except carbohydrates. All carbohydrates were filter sterilized and added to the sterile base medium under aseptic condition. All the test flasks were inoculated with actively growing 15 hours old $10 \% \mathrm{v} / \mathrm{v}$ culture, having cell count of $10^{7}$ cells $/ \mathrm{ml}$. The flasks were incubated on a rotary shaker at $28 \pm 2{ }^{\circ} \mathrm{C}$ for 5 days. Viscosity and production were checked after every $24 \mathrm{~h}$. A comparative study for production of EPS was also performed using EPS medium $(\mathrm{g} / \mathrm{L})$ : caseine hydrolysate 15.0 , sodium acetate $12.0, \mathrm{~K}_{2} \mathrm{HPO}_{4}$ 10.0, yeast extract 5.0, sodium chloride 2.5 , L-cystine 0.5 
and sucrose/glucose/galactose 50.0, pH 7.2 (Atlas and Parks, 1997).Influence of carbohydrate on EPS production was studied by supplementing medium with $30 \mathrm{~g} / \mathrm{L}$ glucose/galactose/sucrose/mannitol. Further concentration of sucrose in the medium was also optimized by providing 30,50 and $70 \mathrm{~g} / \mathrm{L}$ sucrose.

\section{Recovery of EPS}

Cells were harvested from the respective broth medium by centrifugation at $10,000 \mathrm{~g}$ for $10 \mathrm{~min}$. After centrifugation, three volumes of chilled acetone was added into the supernatant and stored overnight at $4{ }^{\circ} \mathrm{C}$. Precipitated material was collected by centrifugation $(10 \mathrm{~min}$ at $10,000 \mathrm{~g})$ and the pellets were dried at 65 ${ }^{\circ} \mathrm{C}$ till constant weight. Dry weight was measured from all the dried pellets (Razack et al., 2013)

\section{RESULTS AND DISCUSSION}

All the colonies on 4 media were observed, based on difference in colony morphology 105 bacterial isolates were selected as EPS producers as they showed slimy gummy colony morphology (Table 1). Out of 105 isolates, 68 bacterial isolates were from fresh samples and 37 from spoiled samples. Medium with sucrose resulted in growth of nearly $50 \%$ of the total isolates. As compared to spoiled fruits or potato peels, fresh samples showed more variety of EPS producers except watermelon sample. In case of sucrose containing medium 6 types of colony reappeared in spoiled samples, whereas in glucose containing medium 3 samples showed reappearance of single isolate. In case of galactose and MRSA none of the samples showed the presence of isolates isolated from fresh sample. During the course of two months storage out of 68 isolates which were isolated from fresh samples $14 \%$ colony reappeared in spoiled samples. A number of bacterial isolates decreased during storage of samples, due to drying of samples as well as the antagonists effect of the survived organisms.

Table 1 Isolates and source of isolation

\begin{tabular}{|c|c|c|c|c|c|c|c|c|}
\hline \multirow[b]{2}{*}{ Source } & \multicolumn{8}{|c|}{ Number of morphologically different colonies picked from yeast extract agar with different cabohydrates and MRS agar (MRSA) } \\
\hline & \multicolumn{2}{|c|}{ Sucrose } & \multicolumn{2}{|c|}{ Glucose } & \multicolumn{2}{|c|}{ Galactose } & \multicolumn{2}{|c|}{ MRSA } \\
\hline Potato peels & $3(1)$ & 1 & 3 & 1 & 2 & 1 & - & - \\
\hline Orange & $4(2)$ & 1 & 2 & 1 & 1 & - & - & - \\
\hline Chikoo & $3(1)$ & 1 & 2 & 1 & 2 & - & - & - \\
\hline Pomegranate & 2 & - & $3(1)$ & 1 & 1 & - & - & - \\
\hline Strawberry & 3 & 1 & 2 & 1 & 1 & 1 & - & - \\
\hline Guava & 1 & 1 & 1 & - & - & 2 & - & - \\
\hline Berry & 1 & 1 & 1 & 1 & 1 & - & - & - \\
\hline Lichee & 3 & 2 & - & 1 & - & - & - & 1 \\
\hline Custard apple & $2(1)$ & 3 & 1 & 1 & - & - & - & 1 \\
\hline Mango & 3 & - & 2(1) & 2 & 1 & 1 & - & - \\
\hline Watermelon & - & 1 & - & - & - & 1 & - & - \\
\hline Total & 32 & 17 & 22 & 12 & 14 & 6 & - & 2 \\
\hline
\end{tabular}

( ) = reappearance of isolate after 60 days of storage.

Amongst the isolates, $87 \%$ isolates were gram positive and $13 \%$ were gram negative, $42 \%$ showed pigmentation and $44 \%$ colonies were opaque. The selected 17 cultures, which gave EPS production more than $0.9 \mathrm{~g} / \mathrm{L}$ were represented by $83 \%$ gram positive bacteria and $17 \%$ gram negative bacteria. Biochemical test and sugar utilization pattern revealed that all the isolates showed casein hydrolysis, and oxidative test positive; where as, ammonia production, deaminase test, decarboxylase test and fermentative test were negative. Out of 17 isolates, 6 isolates were able to produce only acid in all 21 sugars. A similarity index of 17 isolates based on biochemical test and sugar utilization pattern is shown in Table 2

Table 2 Similarity index based on biochemical characteristics and sugar utilization pattern.

\begin{tabular}{|c|c|c|c|c|c|c|c|c|c|c|c|c|c|c|c|c|c|}
\hline \multicolumn{18}{|c|}{$\%$ Similarity } \\
\hline \multicolumn{18}{|c|}{ Isolates } \\
\hline Isolates & 1 & 2 & 3 & 4 & 5 & 6 & 7 & 8 & 9 & 10 & 11 & 12 & 13 & 14 & 15 & 16 & 17 \\
\hline 1 & 1 & 0.55 & 0.57 & 0.64 & 0.37 & 0.71 & 0.6 & 0.6 & 0.62 & 0.37 & 0.6 & 0.55 & 0.62 & 0.46 & 0.6 & 0.46 & 0.57 \\
\hline & & 1 & 0.84 & 0.86 & 0.55 & 0.66 & 0.80 & 0.86 & 0.84 & 0.73 & 0.68 & 0.77 & 0.77 & 0.75 & 0.86 & 0.66 & 0.68 \\
\hline \multicolumn{18}{|l|}{$\mathbf{z z 2}$} \\
\hline 3 & & & 1 & 0.93 & 0.51 & 0.81 & 0.95 & 0.97 & 0.91 & 0.68 & 0.91 & 0.82 & 0.88 & 0.82 & 0.93 & 0.68 & 0.80 \\
\hline 4 & & & & 1 & 0.53 & 0.64 & 0.95 & 0.93 & 0.97 & 0.6 & 0.88 & 0.84 & 0.86 & 0.82 & 0.95 & 0.66 & 0.75 \\
\hline 5 & & & & & 1 & 0.37 & 0.55 & 0.53 & 0.51 & 0.6 & 0.53 & 0.55 & 0.57 & 0.57 & 0.57 & 0.46 & 0.44 \\
\hline 6 & & & & & & 1 & 0.57 & 0.64 & 0.62 & 0.46 & 0.62 & 0.62 & 0.57 & 0.6 & 0.64 & 0.57 & 0.55 \\
\hline 7 & & & & & & & 1 & 0.93 & 0.88 & 0.57 & 0.86 & 0.77 & 0.84 & 0.82 & 0.88 & 0.71 & 0.75 \\
\hline 8 & & & & & & & & 1 & 0.93 & 0.64 & 0.93 & 0.84 & 0.86 & 0.84 & 0.95 & 0.73 & 0.77 \\
\hline 9 & & & & & & & & & 1 & 0.57 & 0.86 & 0.84 & 0.84 & 0.77 & 0.93 & 0.71 & 0.75 \\
\hline 10 & & & & & & & & & & 1 & 0.57 & 0.6 & 0.6 & 0.66 & 0.6 & 0.55 & 0.48 \\
\hline 11 & & & & & & & & & & & 1 & 0.8 & 0.84 & 0.77 & 0.93 & 0.68 & 0.75 \\
\hline 12 & & & & & & & & & & & & 1 & 0.75 & 0.68 & 0.84 & 0.68 & 0.71 \\
\hline 13 & & & & & & & & & & & & & 1 & 0.75 & 0.82 & 0.57 & 0.68 \\
\hline 14 & & & & & & & & & & & & & & 1 & 0.80 & 0.62 & 0.66 \\
\hline 15 & & & & & & & & & & & & & & & 1 & 0.68 & 0.77 \\
\hline 16 & & & & & & & & & & & & & & & & 1 & 0.66 \\
\hline 17 & & & & & & & & & & & & & & & & & 1 \\
\hline
\end{tabular}

Based on biochemical test and sugar utilization characteristics out of 17 cultures none of the culture showed $100 \%$ similarity. The maximum similarity observed was $97 \%$ amongst culture 3 and 8 (C1A and SRA 8), 4 and 9 (SRA 1 and SRA 5), 12 cultures showed more than $80 \%$ similarity, out of these 6 cultures showed more than $90 \%$ similarity. The similarity index of the isolate (SRA 17) was $37 \%$ to $60 \%$; whereas, that of isolate 10 (SRA 15 ) was $37 \%$ to $73 \%$. This data clearly shows the wide diversity of EPS producers isolated from the selected samples. Based on 16S rRNA partial gene sequence, of selected 17 isolates, Bacillus subtilis comprised $25 \%$ of the isolates and if genus Bacillus is considered, it comes out to be near $60 \%$ of the total selected isolates. Remaining $40 \%$ are represented by 7 different genus (Table 3 ). 
Table 3 Identification of selected isolates based on 16S rRNA sequencing

\begin{tabular}{|c|c|c|c|}
\hline Source & $\begin{array}{l}\text { Isolate } \\
\text { code }\end{array}$ & Isolate identified & $\begin{array}{l}\text { GenBank } \\
\text { accession } \\
\text { number }\end{array}$ \\
\hline Potato peels & SRA 18 & Escherichia coli & KTG30840 \\
\hline Sweet lime & SRA 6 & Bacillus tequilensis & KM406457 \\
\hline Chikoo & $\mathrm{C} 1 \mathrm{~A}$ & $\begin{array}{l}\text { Bacillus subtilis subspecies } \\
\text { spizizani }\end{array}$ & KM406418 \\
\hline Custard apple & SRA1 & Bacillus soneresis & KM406421 \\
\hline Spoiled orange & SRA 17 & Xanthomonas campestris & KTG30839 \\
\hline $\begin{array}{l}\text { Spoiled custard } \\
\text { apple }\end{array}$ & SRA 9 & Lactobacillus fermentum & KM406420 \\
\hline Pomegranate & SRA 4 & Bacillus species & KM406429 \\
\hline Sweet lime & SRA 8 & Bacillus methylotrophicus & KM406458 \\
\hline Pomegranate (i) & SRA 5 & Bacillus licheniformis & KM406430 \\
\hline Spoiled guava & SRA 15 & Bacillus subtilis & KP178604 \\
\hline Chikoo 2 & $\mathrm{C} 2 \mathrm{~A}$ & Bacillus subtilis species & KM406419 \\
\hline Spoiled lichee & SRA 3 & $\begin{array}{l}\text { Leuconostoc } \\
\text { pseudomestenteroids }\end{array}$ & KM406428 \\
\hline Mango & SA 100 & Enterobacter cloacae & \\
\hline Orange & SRA 2 & Bacillus amyloliquefaciens & KM406427 \\
\hline Spoiled mango & SRA 7 & Bacillus species & KM406459 \\
\hline Potato peels 1 & SRA 14 & Micrococcus species & KP178617 \\
\hline Orange & SRD 1 & Panebacillus polymyxa & KJ830755 \\
\hline
\end{tabular}

Carbohydrates are the major component of the cytoskeleton and an important nutritional requirement for the growth and cell development. Production of EPS was studied using YE broth containing 3\% sucrose, glucose, galactose and mannitol as a source of carbon. In this study, it was found that irrespective of selected isolates, production of EPS was more than at least 2 fold higher in sucrose containing media as compared to any other sugar used in the media except isolates SRA 3 and SRA 18 (Fig. 1). EPS dry weight production ranged between 0.9 to $5.4 \mathrm{~g} / \mathrm{L}$ in sucrose containing medium; whereas, it was 0.06 to $3.79,0.03$ to $0.99,0.02$ to $0.6 \mathrm{~g} / \mathrm{L}$ in glucose, galactose and mannitol containing medium respectively.

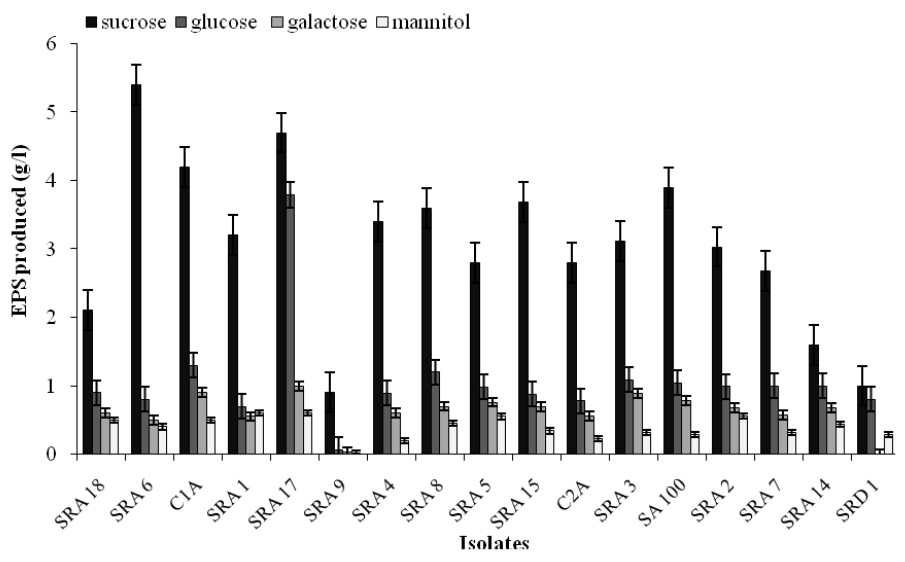

Figure 1 Influence of different sugars on EPS production.

Influence of sucrose concentration on EPS production is shown in Fig. 2. EPS production was 1.06 to 3.8 and 1.2 to 3.5 fold higher in the presence of $5 \%$ sucrose as compared to $3 \%$ and $7 \%$ sucrose in the medium respectively.Variation of EPS production by different isolates in types of sugar used and the concentration of sucrose added in the medium indicates the metabolic and physiological diversity of the isolates and their preference for the sugar as well as concentration of sucrose in the medium.

Comparative study of EPS production between YE broth containing 5\% sucrose and EPS medium was also performed. It was observed that constituents of EPS medium gave a higher production of EPS in comparison to Yeast Extract broth except for isolate SRA17. The differences of EPS produced in the EPS medium as compared to SYE were as small as 1.03 and as high as 4.4 fold (Fig.3). The selection of EPS medium as a medium, sucrose as a source of substrate and $5 \%$ concentration of sucrose resulted in more than 4.4 fold increase in the EPS production. Amongst selected isolates under the experimental conditions, Bacillus species gave higher EPS production as compared to species of Xanthomonas and Leuconostoc obtained in this study, which are reported to be EPS producer.

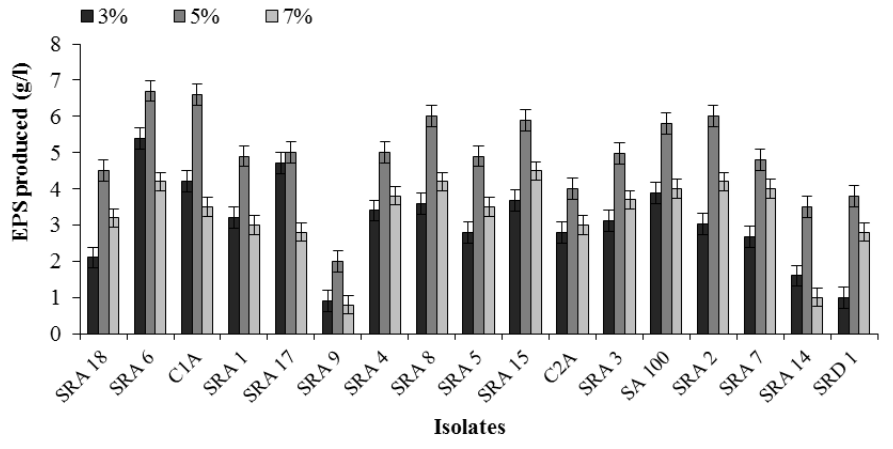

Figure 2 Influence of different sucrose concentration on EPS production.

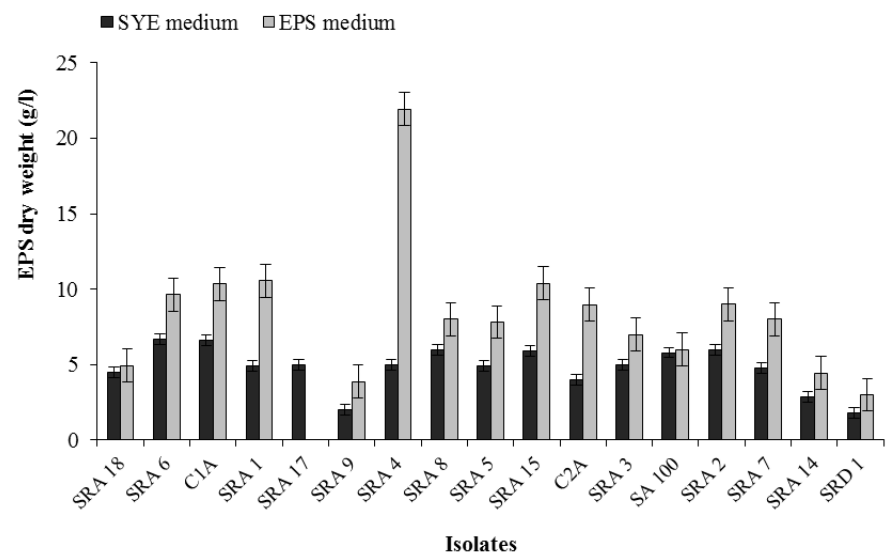

Figure 3 Influence of different medium on EPS production.

Acknowledgement: We are thankful to the Department of Science and Technology (DST), New Delhi for providing the INSPIRE Fellowship to Kinjal Upadhyay and UGC, New Delhi for providing the Emeritus Professor Fellowship to S.R.Dave.

\section{REFERENCES}

ASKARI, G.A., KAHOUADJI. A., KHEDID, K., CHAROF, R., MENNANE, Z. (2012). Screenings of lactic acid bacteria isolated from dried fruits and study of their antibacterial activity. Middle-East J. Sci. Res., 11(2), 209-215.

ASLIM, B., YÜKSEKDAG, Z.N., BEYATLI, Y., MERCAN. N. (2005). Exopolysaccharide production by Lactobacillus delbruckii subsp.bulgaricus and Streptococcus thermophilus strains under different growth conditions. World J. Microbiol. Biotechnol., 21(5), 673-677. http://dx.doi.org/10.1007/s11274-004$\underline{3613-2}$

ATLAS, R.M., PARKS, L.C. (1997). Handbook of Microbiological Media., CRC Pres New York., $2^{\text {nd }}$ edition, 783-965.

BRENNER, D.J., KRIEG, N.R., GARRITY, G., STALEY, J.T. (2005). Bergey's Manual of Systematic Bacteriology (Volume 2) The Proteobacteria, Part B The Gammaproteobacteria, Springer, USA.

FRANZETTI, L., SCARPELLINI, M. (2007). Characterisation of Pseudomonas spp. isolated from foods. Annals Microbiol., 57(1), 39-47.

MARÍN, F.R., SOLER-RIVAS, C., BENAVENTE-GARCÍA, O., CASTILLO, J., PÉREZ-ALVAREZ, J.A. (2007). By-products from different citrus processes as a source of customized functional fibres. Food Chem., 100(2), 736-741. http://dx.doi.org/10.1016/j.foodchem.2005.04.040

MRIDUL, U., PREETHI, K. (2014). Fermentative utilization of fruit peel waste for lactic acid production by Lactobacillus plantarum. Indian J. Appl. Res., 4(9), 449-451.

NGUZ, K., SHINDANO, J., SAMAPUNDO, S., HUYGHEBAERT, A. (2005) Microbiological evaluation of fresh-cut organic vegetables produced in Zambia. Food Control, 16(7), 623-628. http://dx.doi.org/10.1016/j.foodcont.2004.07.001 NWODO, U.U., GREEN, E., OKOH, A.I. (2012). Bacterial exopolysaccharides: functionality and prospects. Int. J. Mol. Sci., 13(11), 14002-14015. http://dx.doi.org/10.3390/ijms131114002

PALACIO-BIELSA, A., ROSELlÓ, M., LLOP, P., LÓPEZ, M.M. (2012). Erwinia spp. from pome fruit trees: similarities and differences among pathogenic and non-pathogenic species. Trees, 26(1),13-29. http://dx.doi.org/10.1007/s00468-011-0644-9

QUESADA, E., BEJAR,V., CALVO, C. (1993). Exopolysaccharide production by Volcaniella eurihalina. Experientia, 49(12), 1037-1041. 
RAZACK, S.A., VELAYUTHAM, V., THANGAVELU, V. (2013). Influence of various parameters on exopolysachharide production from Bacillus subtilis. Int. J. Chem. Tech. Res., 5(5), 2221-2228.

SOSNIK, A. (2014). Alginate particles as platform for drug delivery by the oral route:State-of-the-art. ISRN

Pharmaceutics,

$1-17$.

http://dx.doi.org/ 10.1155/2014/926157

SUTHERLAND, I.W. (1998). Novel and established applications of microbial polysaccharides. Trends Biotechnol., 16(1), 41-46.

TRIAS, R., BAÑERAS, L., BADOSA, E., MONTESINOS, E. (2008a) Bioprotection of Golden Delicious apples and Iceberg lettuce against foodborne bacterial pathogens by lactic acid bacteria. Int. J. Food Microbiol., 123, 50-60. http://dx.doi.org/ 10.1016/j.ijfoodmicro.2007.11.065

TRIAS, R., BAÑERAS, L., MONTESINOS, E., BADOSA, E. (2008b). Lactic acid bacteria from fresh fruit and vegetables as biocontrol agents of hytopathogenic bacteria and fungi. Int. Microbiol., 11, 231-236. http://dx.doi.org/10.2436/20.1501.01.66

VOS, P.D., GARRITY, G., JONES, D., KRIEG, N.R., LUDWIG, W., RAINEY,

F.A., SCHLEIFER, K.H., WHITMAN, W.B., (2009). Bergey's Manual of Systematic Bacteriology (Volume 3) The Firmicutes, Springer, USA.

WEINER, R.M. (1997). Biopolymers from marine prokaryotes. Trends Biotechnol., 15, 390-394.

WRIGHT, C., KOMINOS, S.D., YEE, R.B. (1976). Enterobacteriaceae and Pseudomonas aeruginosa recovered from vegetable salads. Appl. Environ. Microbiol., 3(31), 453-454.

ZHANG, N., WARDWELL, P., BADER, R. (2013). Polysaccharide-based micelles for drug delivery. Pharmaceutics, 5(2), 329-352 http://dx.doi.org/10.3390/pharmaceutics5020329 